\title{
Editorial: Making sense of Nordicness, or making Nordicness?
}

\author{
by Marie Antonsen, Kristine Ask, Anja Johanssen
}

What is Nordic? Does it make sense to talk about Nordic Science and Technology Studies (STS)? If so, what kind of contributions could Nordic perspectives give to global STS and other disciplines? And what elements of the international field of STS are being developed and honed by Nordic scholars?

These are some of the questions we are opening up for debate with the first issue of Nordic Journal of Science and Technology Studies (NJSTS). The first paper by Henrik Karlstrøm and Terje Finstad looks specifically at these questions. They use the Norwegian word 'stedegenhet', roughly translated as 'place-ownness', to discuss the implications of geographically anchoring a discipline. They play with the linguistic content of a word that simultaneously means uniqueness of place, the changeable nature of places and their stubbornness to change. Karlstrøm and Finstad conclude that STS is theoretically well suited for handling interdisciplinary challenges and that the Nordic region is ripe with examples of this. However, the exact nature of 'Nordicness', and whether it is even useful category, is a question that should be investigated empirically, debated, and re-visited during the life of this journal.

At the first Nordic STS conference at Hell, Norway in April of this year, we hosted a panel titled What is Nordic STS?. Answers ranged from interest in the Nordic welfare model to a more general Nordic inferiority complex. Some noted a fascination with technologies that produce heat (rather than let's say food), and a research approach that was either highly pragmatic - or maybe just ahistorical. While others hypothesized that nothing was simply 'nordic'. The diversity of themes in the responses demonstrate the potency of such a question. When we now launch NJSTS it is to be a place where such questions can be deliberated on. We aim to strengthen the standing of STS in the Nordic region, to invite Nordic scholars to showcase their work and position Nordic STS research internationally.

The scope and focus on NJSTS is application and/or development of theory in relation to the study of science and technology, translation and/or rewriting of STS theoretical concepts for a Nordic audience, showcasing theoretical and methodological developments in STS, as well as presentation of new empirical data from a Nordic context. However, the journal will also be of interest to an international audience and we encourage international scholars to contribute with comparative cases and perspectives from other contexts. Journal articles are published in either a Nordic language (for pragmatic reasons only Norwegian, Swedish, Danish) or in English. The editors of NORA - Nordic Journal of Feminist and Gender Research has labelled this strategic Nordicness; "an inclusive strategy of incorporating extra-Nordic articles that compare with, or have direct bearing on, Nordic matters" (Åsberg, Rönnblom, Koobak 2012:2).

While we use the term Nordic freely, and somewhat frequently, it is a concept that holds different meanings depending on topic and field. Nordic refers on one hand to a socio-political reality of the Nordic Council and the Nordic Council of Ministers; formalized cultural and political collaborations between the Nordic countries established after World War II, including Norway, Sweden, Denmark, Finland, Iceland, the Faraoe Islands, Greenland and Åland.' For international audiences it would be relevant to point out that the Nordic countries are looking back at a history of turbulence with wars, alliances and shifting power relations. This includes a union between Sweden and Norway, as well as periods of Danish rule in Norway, Greenland and the Faraoe Islands. In contrast, the contemporary political co-operation is said to be built on "common values and a willingness to achieve results that contribute to a dynamic development and increase Nordic competencies and competitiveness." ${ }^{2}$ One outcome of this is joint research councils, like the Nordic Research Council which has supplied funding for NJSTS.

In our first issue we have explicitly themed the Nordic, with contributions from both Nordic and international STS scholars. In the first article Henrik Karlstrøm and Terje Finstad looks at the state of Nordic STS research. They provide an overview of STS related institutions and activities in Nordic countries, and how different

1 http://www.norden.org/en

2 http://www.norden.org/en/about-nordic-co-operation/nordic-co-operation

Corresponding author: Kristine Ask

Department for Interdisciplinary Studies of Culture, Norwegian University of Science and Technology (NTNU).

7491 Trondheim, Norway.

Email: kristine.ask@ntnu.no

Licensing:

All content in NJSTS is published under a Creative Commons Attribution-ShareAlike 4.o license. This means that anyone is free to share (copy and redistribute the material in any medium or format) or adapt (remix, transform, and build upon the material) the material as they like, provided they follow two provisions:

a) attribution - give appropriate credit, provide a link to the license, and indicate if changes were made.

b) share alike - any remixing, transformation or building upon the material must itself be published under the same license as the original. 
adaptations of STS theories is linked to institutional practices. In the second article Knut Sørensen draws on of four empirical studies on energy policy in the Norwegian context; cars, wind power, hydrogen for transport and carbon capture and storage (CCS), in order to link socialization and domestication to innovation studies. We also present interviews with Harry Collins and Brian Wynne, two prominent figures in the controversy regarding the 'third wave of STS'. They deliberate on and fruitfully disagree about the role of politics within STS and the relationship between established expert knowledge and less publicly verified types of knowledge.

The book reviews cover both theoretical issues (practice theory and the relevance of gender in Information and communication technologies) as well more empirical studies; of environmental politics in Norway and Scandinavian design, respectively. Design historian Kjetil Fallan in Scandinavian Design (reviewed by Maija Mäkikalli), challenges the usefulness and relevance of a term like Scandinavian design, described as a "cleverly crafted concept [which] has led to a disturbingly narrow understanding of Nordic design culture"[p. 1.], meaning characterizations such as "'humane', 'democratic', 'organic' and 'blond'." More than anything, he argues, Scandinavian design is something performed. We could say that goes for "Nordicness" as well.Thus, positioning the Nordic in a journal like NJSTS may be more about performing the Nordic than

\section{References:}

Carroll, M. W. 2011. Why full open access matters. PLoS Biology, 9 (11): e1001210. it is establishing a definition once and for all. Our aim for the inaugural issue is to be a conversation starter about both Nordicness as well as a contribution to ongoing controversies within STS.

NJSTS is an online Open Access Journal published under the Creative Commons License, meaning that all content is free and available for reuse and remixing (presuming correct attribution takes place). Our choice to use an Open Access format is threefold; first and foremost it democratizes scientific knowledge. In the traditional model scientific knowledge becomes intrinsically linked to finance, limiting access to those affiliated with financially strong institutions. In a postindustrial society this exasperates differences between inside/outside, and between north/south and east/west. Secondly it ensures that authors retain the right to distribute and use their own research as they see fit. Thirdly, it is about the communicative element of scientific publishing: "Granting readers full reuse rights unleashes the full range of human creativity to translate, combine, analyze, adapt" (Carrol, 2011:1). This last element in particular is something we encourage in our readers and future contributors, and in line with this we wish to invite responses, recommendations or rebuttals to any of our articles.

With that we welcome you to join our performance of Nordic STS as we present to you the inaugural issue of NJSTS.

Cecilia Åsberg, Malin Rönnblom \& Redi Koobak. 2012. Re-orienting Nordicness, Again. NORA - Nordic Journal of Feminist and Gender Research, 20 (2), 75-77. 